\title{
DETERMINACIÓN DEL SEXO POR ADN EN CINCO ESPECIES DE GUACAMAYOS
}

\author{
Sex Determination by ADN in Five Macaw Species
}

Jacqueline Liza R. ${ }^{1}$, Lenin Maturrano H. ${ }^{1,2}$ y Raúl Rosadio A. ${ }^{1,2,3}$

\section{Resumien}

\begin{abstract}
La determinación del sexo en aves de especies silvestres es de vital importancia para tomar medidas de conservación. En especies donde no existe dimorfismo sexual, es necesario contar con una prueba de sexaje alternativo a los métodos quirúrgicos. En este sentido, con la finalidad de estandarizar una prueba para la determinación del sexo en guacamayos, se desarrolló y evaluó una prueba molecular que consistió en el análisis de ADN mediante la Reacción en Cadena de la Polimerasa (PCR). Para ello, se procedió a la extracción de ADN a partir de muestras de sangre cinco especies de guacamayos (Ara ararauna, Ara chloroptera, Ara macao, Ara militaris y Propyrrhura couloni). A través de la técnica de PCR y el uso de primers específicos, se amplificó regiones conservadas (exones) y secuencias de regiones no conservadas (intrones) del genchd (Chromodomainhelicase-DNA-binding protein), presentes en ambos cromosomas sexuales ( $\mathrm{Z}$ y W), que permiten diferenciar hembras (chd-ZW) de machos (chd-ZZ). Para la amplificación, se optimizaron las condiciones y los ciclos de PCR. Se pudo detectar dos fragmentos entre 300-400 pares de bases en aves hembras y solamente uno en especies machos. Se observó 100\% (31/31) de correspondencia entre el sexaje por métodos convencionales y por análisis de ADN. La prueba molecular fue posteriormente utilizada para sexar a 28 guacamayos de sexo desconocido, incluyendo 11 aves de la especie peruana Propyrrhura couloni.
\end{abstract}

Palabras clave: gen CHD, cebadores P2 y P8, guacamayo, sexo

\section{Abstract}

Determination of sex in wild birds is crucial in developing conservation plans for threatened species. The absence of sexual dimorphism in birds makes impossible to determine sex based on physical characteristics and sexing has traditionally depended upon surgical methods which are highly stressful for the animals. The present study had the purpose of developing of a noninvasive DNA test for sex determination in macaws (guacamayos). Blood samples from five species (Ara ararauna, Ara chloroptera, Ara macao, Ara militaris y Propyrrhura couloni) were studied. DNA was extracted and

\footnotetext{
${ }^{1}$ Laboratorio de Microbiología y Parasitología Veterinaria, Facultad de Medicina Veterinaria, Universidad Nacional Mayor de San Marcos, Lima

${ }^{2}$ CONOPA-Instituto de Investigación y Desarrollo de Camélidos Sudamericanos

${ }^{3}$ E-mail: rrosadio@gmail.com
} 
specific primers were used to amplify both exons and introns of the $c h d$ (chromo-helicaseDNA-binding) gene located on the sex chromosomes of all birds. Females are identified by $c h d-\mathrm{ZW}$ on the $\mathrm{W}$ chromosome and males by $c h d-\mathrm{ZZ}$ on the $\mathrm{Z}$ chromosome. The amplification was carried out by the optimization of the conditions and the PCR cycles. Two fragments of 300-400 bp were detected in female birds and one in males. Sex determined by conventional methods in 31 birds agreed with DNA results. The molecular test was also used to sex 28 macaws of unknown sex, including 11 Propyrrhura couloni.

Key words: CHD gene, P2 and P8 primers, macaw, sex

\section{INTRODUCCIÓN}

En la actualidad, existen más de 9198 especies de aves silvestres, siendo el grupo de animales con mayor biodiversidad mundial. El Perú ocupa el segundo lugar con 1701 especies, siendo Colombia el país con mayor diversidad (Pulido, 1991). El estado peruano (D.S. 034-2004-AG) reconoce la existencia de 172 especies aviares en peligro de extinción, 15 de las cuales pertenecen al orden de las psitácidas, incluyendo a cuatro especies de guacamayos clasificados en situación vulnerable (El Peruano, 2004).

En los guacamayos, como en la mayoría de especies de psitácidos, la determinación del sexo presenta dificultades debido a la ausencia de dimorfismo sexual, por lo cual se torna difícil establecer la formación de parejas de reproducción en cautiverio. Esto disminuye las posibilidades de éxito en el aumento de la población silvestre mediante programas de reintroducción (Kirk, 1997). Ante esta realidad, se cuenta con métodos de sexaje como la endoscopía, determinación de niveles hormonales, cariotipo y la observación del comportamiento; sin embargo, estas técnicas presentan ciertas desventajas como ser traumáticas y estresantes, incapacidad de establecer el sexo de aves jóvenes, complejidad de la prueba y demanda excesiva de tiempo. En tal sentido, una herramienta más eficaz resulta ser el análisis genético. Al contrario de lo que sucede en mamíferos, las aves presentan los cromosomas heterogaméticos (ZW) en las hembras y los machos tienen los homogaméticos (ZZ) (Nicholas, 1987).
El sexaje basado en el análisis de ADN (sexaje molecular) ha evolucionado rápida y positivamente en especies aviares, habiéndose empleado diferentes marcadores para establecer diferencias entre hembras y machos. Inicialmente, se buscó un marcador ligado al sexo para el ave Parus major mediante la técnica del RAPD (Random Amplified Polymorphic DNA), donde se amplificaba una secuencia de ADN del cromosoma W. Esta técnica, sin embargo, amplificaba secuencias de ADN no codificante altamente variable que hacía de la prueba poco confiable, incluso en especies bien relacionadas (Lessells y Mateman, 1998). Posteriormente, informaciones de secuenciamiento de ADN en esta misma especie permitió encontrar un segmento similar al gen chd-1 (Chromodomainhelicase-DNA-binding protein) descrito previamente en ratones (Delmas et al., 1993). Este gen homólogo, designado en aves como $c h d-W$, fue inicialmente utilizado como un marcador molecular para sexaje de aves hembras (Ellegren, 1996).

La demostración de la existencia del gen $c h d$, del mismo tamaño molecular y homólogo en el cromosoma $Z$ en especies machos (Griffiths y Korn, 1997) hizo posible identificar diferencias entre ambas secuencias que permitían usar enzimas de restricción y discriminar ambos sexos (Griffiths et al., 1996). La prueba molecular fue reforzada al identificarse regiones no codificantes (intrones) en el cromosoma $\mathrm{Z}$ permitiendo diseñar cebadores más específicos para especies hembras y machos en una misma reacción de amplificación (PCR), lo que permitió independizarse del uso de enzimas de restricción (Griffiths et al., 1998). 
Es así que se planteó el presente estudio a fin de poder sexar guacamayos por ADN a partir de una muestra de sangre. El sexaje molecular resulta ser un buen método alternativo para el sexaje de estos animales, pues no solamente reduce el estrés del método endoscópico, sino que es menos complejo, más rápido y permite ejecutarse en aves de cualquier edad. Además, el uso de este método facilitará la formación de parejas para reproducción en cautiverio y programas de reintroducción y/o repoblación silvestre, especialmente de aves en peligro de extinción.

\section{Materiales y Métodos}

\section{Lugar de Estudio}

El presente estudio se llevó a cabo en el Patronato del Parque de Las Leyendas «Felipe Benavides Barreda» y en un zoocriadero particular de Lima. El procesamiento y el análisis de las muestras se realizó en las instalaciones del Laboratorio de Biología y Genética Molecular de la Facultad de Medicina Veterinaria de la Universidad Nacional Mayor de San Marcos (FMV-UNMSM), Lima.

\section{Animales y Muestras}

La toma de muestra de sangre de los guacamayos en cautiverio fue realizada durante el control sanitario realizado cada año de manera rutinaria en los dos criaderos. En la estandarización de la prueba de $\mathrm{ADN}$ se trabajó con 31 guacamayos del género Ara previamente sexados mediante métodos tradicionales (29 por sexaje quirúrgico y dos por historia). Además, se utilizaron 28 aves de sexo desconocido para la aplicación de la técnica luego de su estandarización (Cuadro 1).

Se colectó $0.2 \mathrm{ml}$. de sangre de cada ave por punción de la vena braquial, que se colocó en tubos con anticoagulante (EDTA). Las muestras se almacenaron en refrigeración por un periodo de cuatro meses previo a su procesamiento.

\section{Extracción de ADN}

Se extrajo el ADN genómico de las muestras de sangre con el Wizard DNA Isolation kit (Promega) siguiendo el protocolo de extracción del fabricante. Se determinó la cantidad y calidad de ADN (tamaño del fragmento y la cantidad o concentración) comparando diluciones seriadas de la muestra con un marcador de peso molecular conocido (? DNA Hind III, Amresco), y separadas mediante electroforesis en gel de agarosa al $0.8 \%$ con TBE $0.5 \mathrm{X}$.

\section{Amplificación del Gen chd}

La amplificación del fragmento del gen $c h d$ se realizó mediante la reacción en cadena de la polimerasa (PCR) utilizando los cebadores $\mathrm{P} 2$ (5' TCTGCATCGCTAAATCCTTT 3) y P8 (5' CTCCCAAGGATGAGRAAAYTG 3') descritos por Griffiths et al. (1998).

La reacción fue desarrollada siguiendo las condiciones descritas por Griffiths et al. (1998) y, posteriormente, se optimizó realizando algunas modificaciones. Se empleó $20-$ $50 \mathrm{ng}$ de ADN genómico, $1.5 \mathrm{mM}$ de $\mathrm{MgCl} 2$ (Promega), $2 \mathrm{mM}$ de desoxirribonucleótidos (Promega), de 5-20 pmol de cada cebador (Sigma), 0.5-1.5 U de Taq polimerasa (Promega) y $1 \mathrm{X}$ de buffer de PCR (Promega), utilizando los siguientes condiciones de amplificación: 1 ciclo de denaturación inicial a $95^{\circ} \mathrm{C}$ durante $5 \mathrm{~min} ; 30$ ciclos de 95 ${ }^{\circ} \mathrm{C}$ durante $30 \mathrm{~s}, 47^{\circ} \mathrm{C}$ durante 30 s y $72{ }^{\circ} \mathrm{C}$ durante $30 \mathrm{~s}$, con una extensión final de 72 ${ }^{\circ} \mathrm{C}$ durante $7 \mathrm{~min}$.

Para la visualización de los productos de PCR, se diluyeron con Buffer Loading Gel 6X (Promega) a razón de 5:1 y separados en un gel de agarosa (Promega) al 3\% durante 4 horas, a $120 \mathrm{v}$ utilizando solución tampón TBE $0.5 \mathrm{X}$ (Tris borato EDTA) en un sistema de electroforesis horizontal (Hybaid). Los productos de PCR fueron teñidos con bromuro de etidio y visualizados en un transiluminador. Para la lectura de los resultados, la visualización de dos fragmen- 
Cuadro 1. Especies de guacamayos utilizados en el estudio para el sexaje molecular

\begin{tabular}{lcc}
\hline & \multicolumn{2}{c}{ Animales sexados } \\
\cline { 2 - 3 } Especie & Sexo conocido & $\begin{array}{c}\text { Sexo desconocido } \\
\text { (para sexaje molecular) }\end{array}$ \\
\hline Ara ararauna & 11 & 02 \\
Ara macao & 07 & 06 \\
Ara chloroptera & 07 & 03 \\
Ara militaris & 02 & 06 \\
Propyrrhura couloni & 04 & 11 \\
\hline Total & 31 & 28
\end{tabular}

tos en el gel de agarosa al 3\% correspondieron al sexo hembra y la observación de un fragmento a individuos machos (Griffiths y Tiwari, 1995).

\section{Resultados}

Se extrajo el material genético (ADN) en una concentración que varió entre 25 a 50 $\mathrm{ng} / \mu \mathrm{L}$ en las 59 muestras de sangre de las cinco especies de guacamayos en estudio. La visualización en gel de agarosa (3\%) de los productos de la PCR utilizando los cebadores P2 y P8 determinó la presencia de dos fragmentos de 300 a 400 pares de bases en las 14 guacamayos hembras y de un fragmento de 300 a 400 pares de bases en los 17 individuos machos, que en ambos casos habían sido sexados por pruebas convencionales (Fig. 1). De esta manera, se obtuvo el $100 \%$ de compatibilidad entre los resultados obtenidos por métodos de sexaje molecular y otros métodos de sexaje.

Paralelamente, en el grupo de 28 aves de sexo desconocido, se visualizaron dos fragmentos en 15 de estas aves y de un fragmento en las 13 aves restantes, correspondientes a individuos hembras y machos, respectiva- mente. Estos fragmentos tuvieron el mismo peso molecular que los fragmentos obtenidos en el grupo de aves de sexo conocido empleadas para la estandarización de la prueba (Fig. 1).

\section{Discusión}

El uso de los cebadores denominados P2 y P8 permite amplificar dos regiones del gen chd presentes en los cromosomas sexuales de las aves (Griffiths et al., 1998). Uno de ellos amplifica regiones altamente conservadas (exones) y el otro regiones no conservadas (intrones) permitiendo la amplificación de hasta dos segmentos en individuos hembras y solamente un fragmento en machos.

En este estudio, se pudo contar con individuos de sexo conocido para estandarizar la prueba en una primera etapa, de manera muy similar a la metodología empleada en estudios realizados en aves relacionadas (Miyaki et al., 1998). A pesar que las muestras permanecieron conservadas en condiciones de refrigeración por cuatro meses, su posterior empleo no alteró la calidad del ADN de las aves, lo cual es importante si se trabajan muestras de especies en situación crítica o 


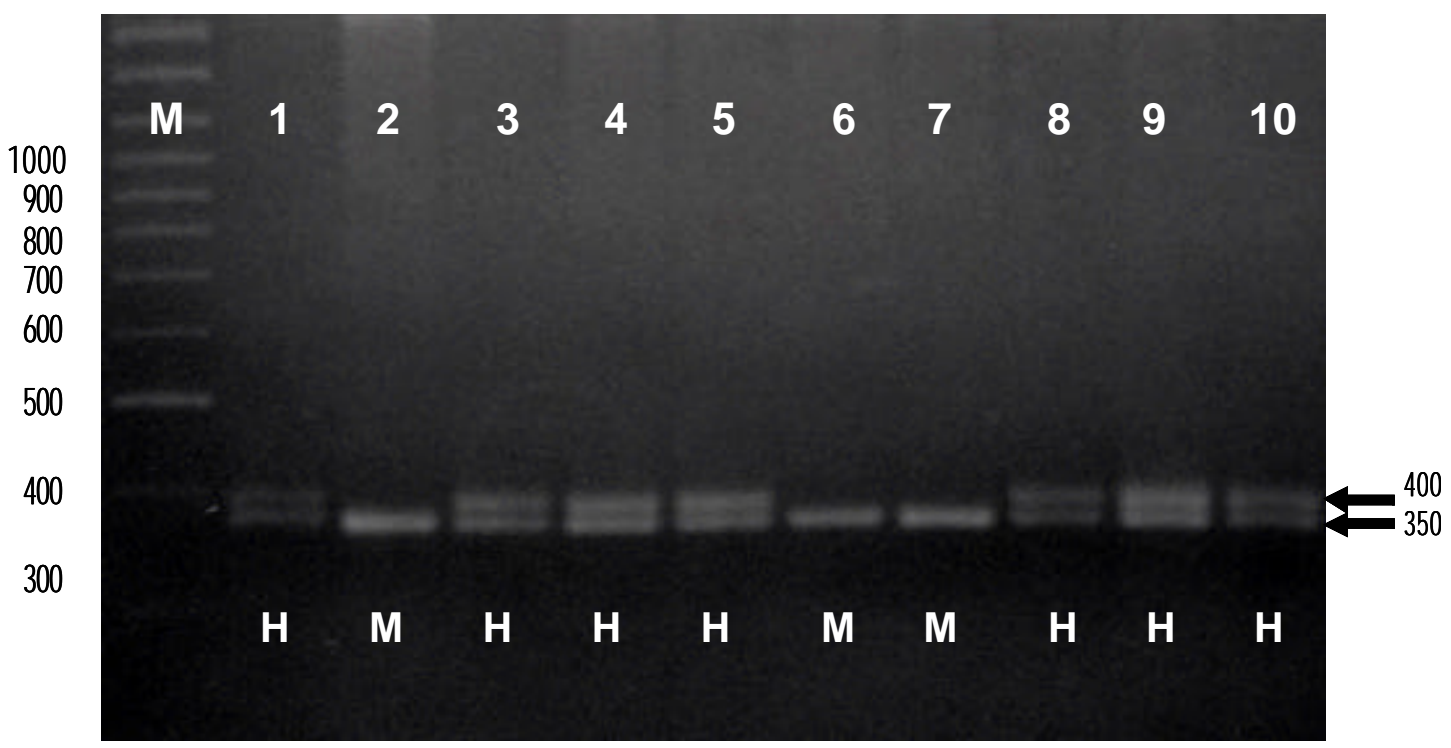

Figura 1. Visualización de los productos amplificados por PCR de guacamayos de sexo conocido en gel de agarosa al 3\%. La presencia de dos fragmentos (bandas) entre 400 y 300 bp corresponden a aves hembras (H) y una banda para aves machos (M). En la fila superior se encuentra la identificación de las especies de guacamayos, 1 y 2: Propyrrhura couloni; 3 y 7: Ara ararauna; 4 y 6: Ara chloroptera; 5: Ara militaris; 8, 9 y 10: Ara macao. M: marcador de peso molecular de $100 \mathrm{pb}$.

en peligro de extinción. Así mismo, se observó una concordancia del $100 \%$ entre los resultados de sexaje por pruebas moleculares y por métodos convencionales (sexaje quirúrgico e historia) en el grupo de aves de sexo previamente conocido.

El estudio tiene un impacto potencial en el manejo reproductivo de estas especies. El número adecuado de parejas reproductivas en una población puede ser mejor evaluado si se conoce la proporción de sexos (relación machos: hembras). Esta información es vital en especies en peligro de extinción de una gran mayoría de especies monógamas, pues se podría determinar el tamaño de la siguiente generación (Miyaki et al., 1998). En esta investigación se demuestra que las pruebas moleculares son una importante herramienta que puede ser usada en la conservación de familias de aves en peligro de extinción. Así mismo, estos métodos son valiosos para los programas de reproducción en cautiverio y en zoológicos que bien pueden aplicarse para posteriores estudios de comportamiento.

Los trabajos de investigación en biología molecular han contribuido directamente en la conservación de especies amenazadas. El caso del Guacamayo de Spix (Cyanopsitta spixii) es relevante, pues se pudo determinar el sexo del último ejemplar en vida libre (resultó ser un macho) y lograr la reintroducción de esta especie (Griffiths et al., 1998). En la presente investigación se determinó el sexo de ejemplares de una especie vulnerable y propia del Perú, el guacamayo de cabeza azul (Propyrrhura couloni), el cual representa el primer reporte científico de sexaje molecular para esta especie. 


\section{Conclusiones}

? Se estableció la prueba de sexaje molecular mediante amplificación del gen chd para la determinación del sexo en especies de guacamayos silvestres en el Perú.

? Se reporta por primera vez el sexaje molecular de 15 ejemplares de la especie peruana Propyrrhura couloni, de situación vulnerable en el Perú.

\section{Agradecimientos}

Los autores expresan su agradecimiento al Patronato del Parque de las Leyendas y a CONOPA, quienes permitieron la ejecución del presente estudio, y a los MV A. Manchego, M. Alba y J. Rodríguez por la asesoría prestada.

\section{Literatura Citada}

1. Delmas V, Stokes DG, Perry RP. 1993. A mammalian DNA-binding protein that contains a chromodomain and a SNF2/ SW12 like helicase domain. Proc Natl Acad. Sci 20: 2414-2418.

2. El Peruano. 2004. Aprueban categorización de especies amenazadas de fauna silvestre y prohíben su caza, captura, tenencia, transporte o exportación con fines comerciales. D.S. No 034-2004AG. El Peruano 22 de setiembre - Normas Legales. p 276853- 276855.
3. Ellegren H. 1996. First gene on the avian $\mathrm{W}$ chromosome (CHD) provide a tag universal sexing of non-ratite birds. Proc R Soc Lond Biol Sci 263: 16351641.

4. Griffiths R, Tiwari B. 1995. Sex identification of the last wild Spix's macaw. Nature 375: 454-455.

5. Griffiths R, Daan S, Dijkstra C. 1996. Sex identification in birds using two CHD genes. Proc Royal Society London B 263: 1249-1254.

6. Griffiths R, Korn R. 1997. A CHD1 gene $\mathrm{Z}$ chromosome linked in the chicken (Gallus domesticus). Gene 197: 225-229.

7. Griffiths R, Double MC, Orr K. 1998. A DNA test to sex most birds. Mol Ecol 7: 1071-1075.

8. Kirk RW. 1997. Terapéutica veterinaria de pequeños animales. México DF: Ed. Mc Graw-Hill Interamericana. 1556 p.

9. Lessells C, Mateman A. 1998. Sexing birds using random amplified polymorphism DNA (RAPD) markers. Mol Ecol 7: 187-195.

10. Miyaki YM, Griffiths $R$, Orr K, Nahum LA, Pereira SL, Wajntal A. 1998. Sex identification of parrots, toucans and curassows by PCR: perspectives for wild and captive population studies. Zoo Biol 17: 415-423.

11. Nicholas FW. 1987. Genética Veterinaria. Zaragoza: Acribia. 636 p.

12. Pulido V. 1991. El libro rojo de la fauna silvestre en el Perú. Lima: Ed. Maijosa. $219 \mathrm{p}$. 